\title{
RİSALE-İ ELFAZ-I KÜFÜR'DEKİ TÜRKÇE ARKAİK UNSURLAR*
}

Irfan $A L A N^{* *}$

\section{Özet}

Bir dilin arkaik unsurları, o dili konuşan toplumların kültür ve dil zenginliği hakkında bilgi edinmemizi sağlar. Bir gramer terimi olarak arkaik, Türkçe Sözlük'te "Konuşulan ve yazılan dilde, kullanımdan düşmüş olan (eski söz veya deyim)" şeklinde açıklanmıştır. Yapılan bu çalışmada, Türk Dil Kurumu Yazma Eserler Arşivine kayıtlı A55 nolu Risale-i Elfaz-1 Küfür adlı eserin söz varlığında görülen arkaik unsurlar inceleme konusu edilmiştir. Eserde geçen bir sözü arkaik unsur olarak belirlemek için, o sözün bugünkü Türkiye Türkçesi standart yazı dilinde kullanımdan düşmüş ve Türkçe Sözlükte yer almamış olması, ölçüt olarak kullanılmıştır. Örneğin "ol dahı bu garāmeti kime vireyin dise kāfir olur" ifadesindeki 1. teklik şahıs emir/istek eki -eyin ekinin kullanımı Eski Türkçeye kadar götürülebilirken, günümüz Türkiye Türkçesi yazı dilinde kullanımdan düşüp, yerini -eyim ekine bırakmıştır.

Bu çalışmada Risale-i Elfaz-1 Küfür'de tespit edilen arkaik unsurlar, eklerde ve kelimelerde görülen arkaik unsurlar şeklinde iki ana başlık altında incelenmiştir.

Anahtar Kelimeler: Arkaik, Eski Türkçe, Risale-i Elfaz-1 Küfür

\section{TURKISH ARCHAIC WORDS IN “RİSALE-İ ELFAZ-I KÜFÜR”}

\begin{abstract}
The archaic words of a language enable us to learn about the cultural and linguistic richness of the communities that speak that language. As a grammatical term, archaic is explained in the Turkish Dictionary as follows: "old word or idiom that has fallen out of use in the spoken and written language". In this study, when we compare it to the present day in the vocabulary of Risale-i Elfaz-1 Küfür A55, which is registered in the Turkish Language Institution Manuscripts Archive, the words that become archaic, are examined. İn order to determine a word that used in Risaale-i Elfaz-1 Küfür as archaic, based on the following criteria; the word should not be used in today Turkey Turkish written language and should not take place in Turkish dictionary. For example, in this sentence: "ol dahı bu garāmeti kime vireyin dise käfir olur" the using of I. singular personal imperative -eyin can be seen in Old Turkish but today it has fell from use and it replaced by -eyim. The archaic elements identified in Risale-i Elfaz-1 Küfür are examined under two main headings; as archaic elements seen in suffixes and words.
\end{abstract}

Key Words: Archaic, Old Turkish, Risale-i Elfaz-1 Küfür.

\footnotetext{
* Bu makale 2018 yılında Fırat Üniversitesi Sosyal Bilimler Enstitüsü Yeni Türk Dili Anabilim Dalında Dr. Öğr. Üyesi Mehmet Özeren danışmanlığında hazırlanan Risale-i Elfaz-ı Küfür (İnceleme-Metin-Sözlük) adlı yüksek lisans tezinden üretilmiştir.

** Doktora Öğrencisi, Fırat Üniversitesi Sosyal Bilimler Enstitüsü Türk Dili ve Edebiyatı Bölümü, Yeni Türk Dili Anabilim Dal1, el-mek: irfan.alan12@gmail.com
} 


\section{Giriş}

Risale-i Elfaz-1 Küfür, Bedr er-Reşid Muhammed b. İsmail'in Arapça yazdığ1 Risâle fi'l-elfâzi'l-küfür adlı eserin Osmanlı Türkçesine yapılan bir tercümesidir. Eserde mütercimin adı ve eserin tercüme edildiği tarih hakkında herhangi bir bilgi bulunmamaktadır. Eserin içeriği çeşitli fetva kitaplarından alınmış bilgilerden oluşmaktadır. Bu bilgiler çeşitli fıkıh âlimlerinin verdiği fetvalardır. Eserde bu fetvalar esas alınarak küfür lazım gelen sözlere yer verilmiş ve niçin küfür lazım geldikleri açıklanmıştır. Eserde küfür lazım gelen sözlerin yanı sıra, imanın şartlarından ve İslam'ın şartları gibi konulara da yer verilmiştir (Alan, 2018:3).

Bir dilin yapısı incelenirken artzamanlı ve eşzamanlı yöntemler takip edilir. Bir dili ortaya çıktığı ilk andan en son anına kadar geçen süre içerisindeki tüm değişikleriyle incelemeye artzamanlı inceleme, bir dilin hâlihazırdaki durumun incelenmesine eşzamanlı inceleme denir (Demirci, 2015:60). Bir dili artzamanlı olarak incelemek ancak o dilin yazılı kaynakları üzerinden mümkündür. "Türkçe (Gök)Türk, Uygur, Arap, Latin, Kiril alfabeleri başta olmak üzere, 10'dan fazla alfabe ile yazıya geçirilmiş, yazılı metinleri dünyanın çok değişik coğrafyalarında çok sayıda kütüphanede ve müzede saklanan bir dildir" (Buran, Alkaya, 2015:31). Farkl1 kütüphane ve müzelerde saklanan Türkçe eserler, gün yüzüne çıkmaya muhtaçtır. Zira bu eserlerde Türkçenin zengin söz varlığı ve Türk toplumunun duyuş-düşünce şekli mevcuttur. $\mathrm{Bu}$ eserler artzamanlı incelendiği takdirde, Türkçenin arkaik unsurları da gün yüzüne çıkar. Bir dilin arkaik unsurları, o dili konuşan toplumların kültür ve dil zenginliği hakkında bilgi verir.

Fransızcadan Türkçeye geçen arkaik (archaïque) kelimesi Güncel Türkçe Sözlük'te şu şekilde açıklanıştır: 1. sıfat "Güzel sanatlarda klasik çağ öncesinden kalan", 2. sıfat, edebiyat "Konuşulan ve yazılan dilde, kullanımdan düşmüş olan (eski söz veya deyim)" (Güncel Türkçe Sözlük, 2019). Çalışmada söz konusu olan arkaik, bir gramer terimi olan arkaiktir. Zeynep Korkmaz'ın "Gramer Terimleri Sözlügü" adlı eserinde arkaik maddesi bulunmamasına karşın, Korkmaz, arkaik terimi yerine eskicilik, eskilik, eski kelime gibi terimler kullanmıştır: "eskicilik: Eskiye bağlılık, artık kullanılıştan düşmüş olan eski kelimeleri veya kelimelerin eski biçimlerini kullanma; kalıntı kelimeleri kullanma. eskilik: Eskiden kalma; yazı ve konuşma dilinde artık kullanılıştan düşmüş olan, dilin daha eski veya tarihî devirlerine ait kelime, deyim ve şekiller. eski kelime: Bugün artık kullanılıştan düşmüş bulunan veya eski biçimi ile kullanılan kelime" (Korkmaz, 1992: 55).

Çalışmanın sınırlılığını belirlemek için, kıyaslamada ağız söz varlığı değil, yazı dilinin söz varlığı esas alınmıştır. Yani Risale-i Elfaz-1 Küfür'deki bir kelimenin ya da ekin arkaik unsur saymak için, kelimenin ya da ekin bugünkü Türkiye Türkçesi yazı dilinde kullanımdan düşmüş olması ve Türkçe sözlükte yer almaması ölçüt olarak kullanılmıştır.

Yapılan bu çalışmada Risale-i Elfaz-1 Küfür'ün söz varlığındaki günümüz Türkiye Türkçesine göre kıyasladığımızda arkaik olan Türkçe kelimeler ve ekler tespit edilmiştir. Tespit edilen arkaik unsurların tarihî Türk lehçelerindeki şekilleri de verilmeye çalışılmıştır. Tarihî Türk lehçelerindeki şekillerini tespit etmek için eklerde, gramer kitapları; kelimelerde ise sözlükler ve dönemin eserleri taranmıştır. Risale-i Elfaz-1 Küfür'de tespit edilen arkaik unsurlar, eklerde ve kelimelerde görülen arkaik unsurlar şeklinde iki ana başlık altında incelenmiştir: 


\section{Eklerde Görülen Arkaik Unsurlar:}

-AyIn: 1. tekil şahıs istek kipidir. Bu ek Kıpçak Türkçesi hariç bütün tarihî Türk lehçelerinde sıklıkla kullanılmıştır. Köktürkçede +AyIn (Tekin, 2003:50), Eski Uygur Türkçesinde -AyIn (Şen, 2014:66), Karahanlı Türkçesinde -AyIn (Hacieminoğlu, 2013:190), Eski Anadolu Türkçesinde -AyIn ekinin yanı sıra -AyIm (Korkmaz, 2013:101), Harezm Türkçesinde -AyIn nadiren +AyIm ünlü ile biten kök veya gövdeden sonra -ġayın/gäyin (Eckmann, 2014:27), Kıpçak Türkçesinde -AyIm, gayım/geyim (Karamanlığlu, 1994:116), Çağatay Türkçesinde +AyIn -Ay, -AyIm (Eckmann, 1988:119) şekilleri kullanılmıştır.

Türkiye Türkçesi yazı dilinde yerini tamamen -AyIm şekline bırakan bu ek, Risale-i Elfaz-1 Küfür'de de s1klıkla kullanılmaktadır; vireyin 22b/12, ideyin 21b/11, göreyin 25b/3 (RK)

-gIl: 2. tekil şahıs emir kipidir. Bütün tarihî Türk lehçelerinde kullanılmıştır. Köktürkçede -gIl (Tekin, 2014:20), Eski Uygur Türkçesinde -gIl (Şen, 2014:67), Karahanlı Türkçesinde -gIl, gIn (Hacieminoğlu, 2013:190), Eski Anadolu Türkçesinde -gIl (Korkmaz, 2013:101), Harezm Türkçesinde -GIl, GUl, ḳ1, GIn (Ata, 2012:78), Kıpçak Türkçesinde -GIl, -GUl, KIn, -KIl, -GIn (Karamanlıŏlu, 1994:116), Çağatay Türkçesinde -g̈Il, -g்In, -KIn, -KIl (Eckmann, 1998:118).

Türkiye Türkçesi yazı dilinde kullanımdan düşen bu ek, Risale-i Elfaz-1 Küfür'de sadece iki yerde geçer; $\bar{a} g \bar{a} h$ olg̀ll 34a/7, bilgil 1b/4 (RK)

+n: Belirtme hâl ekidir. Bütün tarihî Türk lehçelerinde kullanımı tespit edilmiştir. Köktürkçede $+n$ (Tekin, 2003: 108), Eski Uygur Türkçesinde sadece 3 . tekil şahıs iyelik eklerinden sonra $+n$, onun dişında $+\mathrm{g}$, $+\mathrm{nI}$ (Şen, 2014:62), Karahanlı Türkçesinde $+\mathrm{n}$ yanı sıra $+\mathrm{g} /+\dot{\mathrm{g}}, \quad+\mathrm{nI}$ (Hacieminoğlu, 2013:29), Eski Anadolu Türkçesinde $+\mathrm{I},+\mathrm{nI}$ 3.tekil şahıs ekinden sonra umumiyetle $+\mathrm{n}$ (Korkmaz, 2013:95), Harezm Türkçesinde $+n$ yanı sıra nI (Ata, 2012:61), Kıpçak Türkçesinde $+n$ yanı sıra $+n I$ (Karamanlıŏlu, 1994:77), Çağatay Türkçesinde $+n$ yanı sıra +nI (Eckmann, 1998:63).

Türkiye Türkçesi yazı dilinde kullanımdan düşen bu ek, Risale-i Elfaz-1 Küfür'de sadece 3. tekil şahıs iyelik eklerinden sonra kullanılmıştır; olduġın 18b/3, yerin 40a/2, avretin 13a/3, āvāzesin 30a/12, āyetin 10a/2 (RK).

-IcAK: Eski Anadolu Türkçesinden itibaren kullanılan bir ektir. Ayrıca Eski Anadolu Türkçesi dönemde ekin -Az eki ile genişletilip, tezlik görevinde kullanıldığ da görülür; -caġaz (Korkmaz, 2013:103). Diğer tarihî Türk lehçelerinde bu ekin kullanılmaması, ekin Batı Türkçesine özgü bir ek olduğunu gösterir.

Türkiye Türkçesi yazı dilinde kullanımdan düşen bu ek, Risale-i Elfaz-1 Küfür'de sadece iki yerde geçmektedir; elin ayaġın șalıcak 30b/2, áadd idicek mürtedddür 31b/7 (RK)

-dUkdA: Karahanlı Türkçesinden itibaren kullanılan bir ektir. -dIk/-dUk sıfatfiil ekinin bulunma hâl ekiyle genişletilmesinden oluşan bu ek, Eski Anadolu ve Osmanlı Türkçesinde sıklıkla kullanıldığı halde, Türkiye Türkçesi yazı dilinde bu biçimiyle kullanımdan düşmüş, yerini sıfat-fiil ile bulunma durumu eki arasına birinci, ikinci ve üçüncü şahıs iyelik eki almış şekillere bırakmıştır; dığında/diğinde (Korkmaz, 2014:879). Karahanlı Türkçesinde -dUkdA, -tuḳda (Hacieminoğlu, 2013:175), Eski Anadolu Türkçesinde -dUkdA (Korkmaz,2013:103) 
Türkiye Türkçesi yazı dilinde kullanımdan düşmüş bu ek, Risale-i Elfaz-1 Küfür'de sıklıkla kullanılır; diledükde 3a/2, öldükde 4b/12, geldükde 22a/5, didükde 19b/3, dinildükde 22a/10, oldukda 11b/13 (RK).

+idUK: Eski Uygur Türkçesinden Harezm Türkçesi dönemine kadar fiillerin yanı sıra er- (> i-) "ol-" yardımc1 fiiliyle birlikte isimlere eklendiği görülmüştür. Bu dönemden sonra Eski Anadolu Türkçesinde hem ek fiil yardımıyla hem de ek fiilsiz (dUK) şekliyle isimlerin üzerine gelmiştir. Eski Anadolu Türkçesindeki bazı örnekleri şunlardır; han ķız aydur: Ķazan oğlan avda idügin andan bileyin, șor aña sen ol dèye uşbu işi / Ol dèye kimdügin suçlu kişi ((Salan, 2012:2700).

Türkiye Türkçesi yazı dilinde kullanımdan düşen bu ek, Risale-i Elfaz-1 Küfür'de sıklıkla kullanılmıştır; dahı harām idügini bilüp duāa eylese 22b/4, hemān bir kerre sāḥir idügin iḳāar eylese 25a/3, lüțf idügi kamerden zāahir ve güneşden rūşen 38b/11 (RK).

\section{Kelimelerde Görülen Arkaik Unsurlar:}

a: Eski Türkçede "ol” zamiri hâl ekleriyle çekimlenince "a” biçimine dönüşür. Eski Anadolu Türkçesinden sonra, Osmanlı Türkçesi içerisinde de belli bir süre böyle devam eden bu durum, daha sonra Türkiye Türkçesinde "o" biçimine dönüşerek şimdiki halini almıştır (Küçük, 2014:3). Tarihî Türk lehçelerinin tamamında "ol" zamiri hâl ekleriyle çekimlendiğinde "a" şeklini almıştır; Köktürkçede anta (Tekin, 2003:121), Eski Uygur Türkçesinde anıng (Şen, 2014:64), Karahanlı Türkçesinde anı (Arat, 2006:61), Eski Anadolu Türkçesinde an1 (Özkan, 2014:62), Harezm Türkçesinde anı (Eckmann, 2014:19), Kıpçak Türkçesinde anı (Karamanlıoğlu, 1994:86), Çağatay Türkçesinde anı (Eckmann, 2014:122)

Risale-i Elfaz-1 Küfür'de tespit edilen örnekler şunlardır; andan 17a/13, anda 10b/5, anı 27b/10, anlar 2a/11, anıñ 15b/2 (RK)

aşaġa: "Orhun Türkçesi ve Eski Uygur Türkçesi metinlerinde rastlanmayan bu kelimeye ilk olarak Divânü Lugâti't-Türk'te rastlanmaktadır. Divânü Lugâti'tTürk'te "aşak" şeklinde geçen kelimeye Kâşgarlı Mahmud "Oğuzcada dağ eteği" biçiminde anlamlandırmıştır" (Kaya, 2016:159). Tarihî̂ Türk lehçelerinin tamamında tespit edilemeyen bu kelime, Karahanlı Türkçesinde aşaḳ (Atalay, 1985:66), Eski Anadolu Türkçesinde aşag̉a (Özkan, 2014:70), Harezm Türkçesinde aşaḳ (Yüce, 1993:93), Kıpçak Türkçesinde aşaḳ, aşaġ, aşag̉a, aşaġı, aşaḳa, aşaḳaḳ (Toparlı, Vural, Karaatl1, 2014:14) şekillerinde kullanılmıştır.

Türkçesinde Türkiye Türkçesi yazı dilinde "aşağı" biçimine dönüşen bu kelime Risale-i Elfaz-1 Küfür'de sadece bir yerde geçer ve aşağı anlamında kullanılır; aşaga 18a/5 (RK)

berkişdür- : $\mathrm{Bu}$ fiil, Eski Uygur Türkçesinden itibaren kullanımı tespit edilen ve güçlü, kuvvetli anlamlarına gelen bärk sözcügünden türemiştir. Eski Uygur Türkçesi bärk (Caferoğlu, 2015:39), Karahanlı Türkçesinde berkitmek (Atalay, 1985:340), Eski Anadolu Türkçesinde berkit- (Özkan, 2014:102), Harezm Türkçesinde berkit- berki- (Yüce, 1993:1001), Kıpçak Türkçesinde berkid-, berkin-, berkiş-, berkit-(Toparl1, Vural, Karaatl1, 2014:28).

Türkiye Türkçesi yazı dilinde "pekiştirmek" şekline giren bu kelime Risale-i Elfaz-1 Küfür'de sadece bir yerde geçer; i tikāadın berkişdüre 3a/1 (RK) 
edük: Edik veya edük, ayakkabı için kullanılan ilk kelimelerden biridir. Tarihî Türk lehçelerinin tamamında kullanımı tespit edilemeyen bu kelimenin en eski şekli Eski Uygur Türkçesi metinlerinde mevcuttur. Eski Uygur Türkçesinde "ätük" şeklinde geçen kelimeyi, Ahmet Caferoğlu, Eski Uygur Türkçesi Sözlüğü'nde "edik, terlik, ayakkabı" şeklinde açıklamıştır (Caferoğlu, 2015:78). Karahanlı Türkçesinde etük (Atalay, 1985:68), Eski Anadolu Türkçesinde edük (Gaddar, 2012:364), Harezm Türkçesinde etük (Yüce, 1993:121), Kıpçak Türkçesinde edük, etik, etük, itük (Toparl1, Vural, Karaatl1, 2014:70).

Türkiye Türkçesi yazı dilinde kullanımdan düşen bu kelime, Risale-i Elfaz-1 Küfür'de de geçmektedir; edük 4a/7 (RK)

eyit-: Kökeni Köktürkçeye kadar götürülebilen bu fiil, Tarihî Türk lehçelerinin tamamında sıklıkla kullanılmıştır. Köktürkçe ayt-, ay- (Tekin, 2003:239), Eski Uygur Türkçesinde ayıt- (Caferoğlu, 2015:28), Karahanlı Türkçesinde ay-, ayıt-, ayt- (Üşenmez, 2006:141), Eski Anadolu Türkçesinde eyt-, eyit- (Özkan, 2014:219, Harezm Türkçesinde ay-, ayt- (Yüce, 1993:95-96), Kıpçak Türkçesinde ay-, ayt-, ayıt-, eyit-, iyid- (Toparlı, Vural, Karaatl1, 2014:17), Çağatay Türkçesinde ay-, ayt- (Eckmann, 2014:248).

Türkiye Türkçesi yazı dilinde kullanımdan düşen bu fiil, Risale-i Elfaz-1 Küfür'de sıklıkla kullanılmıştır; eydür 10b/2 (RK)

güyegü: Eski Uygur Türkçesinde "küdägü" (Caferoğlu, 2015:120) şeklinde kullanılan kelime, Karahanlı Türkçesinde küdegü (Üşenmez, 2006:297), Eski Anadolu Türkçesinde güyegü (Özkan, 2014:264), Harezm Türkçesinde küdegü (Eckman, 2014:220), Kıpçak Türkçesinde güyegü, küyegü, küyev, küyöv (Toparl1, Vural, Karaatl1, 2014:88), Çağatay Türkçesinde küyev (Güzeldir, 2002:454).

Türkiye Türkçesi yazı dilinde "güvey, güveyi" şeklinde kullanılan kelime, Risale-i Elfaz-1 Küfür'de güyegü 18a/4 (RK) şeklindedir.

kaçan: Eski Uygur Türkçesinden itibaren kullanılan bu soru zarfı, "ne zaman" anlamına gelmektedir. Eski Uygur Türkçesinde ķaçan (Caferoğlu, 2015:160), Karahanlı Türkçesinde ḳaçan (Atalay, 1985:207), Eski Anadolu Türkçesinde kaç̧an (Özkan, 2014:295), Harezm Türkçesinde ḳaçan (Eckmann, 2014:193), Kıpçak Türkçesinde kaçan, haçan, haş̧an, ḳaşan (Toparl1, Vural, Karaatl1, 2014:122), Çağatay Türkçesinde k kaçan (Eckmann, 1988:264).

Türkiye Türkçesi yazı dilinde kullanımdan düşen bu kelime Risale-i Elfaz-1 Küfür'de kullanılmıştır; ḳaçan 25b/12 (RK)

kanda: Eski Uygur Türkçesi döneminden itibaren kullanılan bu kelime "nerede" anlamına gelen bir soru zarfıdır. Eski Uygur Türkçesinde ḳanta, ḳanda (Caferoğlu, 2015:164), Karahanlı Türkçesinde ḳanda (Üşenmez, 2006:244), Eski Anadolu Türkçesinde ḳanda (Özkan, 2014:306), Harezm Türkçesinde ḳanda (Eckmann, 2014:199), Kıpçak Türkçesinde ḳanda (Toparlı, Vural, Karaatl1, 2014:125), Çağatay Türkçesinde ḳanda (Berbercan, 211:456).

Türkiye Türkçesi yazı dilinde kullanımdan düşen bu kelime, Risale-i Elfaz-ı Küfür'de kullanımı tespit edilmiştir; ḳanda 14b/8 (RK)

kimesne: "Kimesne" (Özkan, 2014:344) biçimiyle Eski Anadolu Türkçesi döneminden itibaren kullanılan kelime, Harezm Türkçesinde kimerse (Yüce, 1993:145), Kıpçak Türkçesinde kimesne, kimersene, kimese, kimirse (Toparl1, Vural, Karaatlı, 2014:148), Çağatay Türkçesine kimerse (Berbercan, 2011:425) şekillerinde kullanılmıştır. 
Türkiye Türkçesinde "kimse" şekline dönüşen bu kelime, Risale-i Elfaz-1 Küfür'de tespit edilmiştir; kimesne 10b/12 (RK)

kovucılıḳ: Eski Anadolu Türkçesinde "dedikodu yapmak" anlamına gelen "kovla-" (Özkan, 214:356) fiilinden türeyen ve dedikoduculuk anlamına gelen bu kelime, mevcut şekliyle tarihî Türk lehçelerinde tespit edilememiştir. Kelime Divan-1 Lügati't-Türk'te geçen "kovı", "ḳowı" (içi kof ve çürümüş olan) kelimeleriyle ilişkili olabilir. Kelimenin kökü olan ḳov- fiili, Eski Anadolu Türkçesinde kovla-(Özkan, 214:356), Kıpçak Türkçesinde ḳov- (Toparlı, Vural, Karaatl1, 2014:155).

Türkiye Türkçesi yazı dilinde kullanılmayan bu kelime Risale-i Elfaz-1 Küfür'de bir yerde geçmektedir; ḳovuculıḳ 38a/2 (RK)

ol: Tarihî Türk lehçelerinde hem işaret zamiri hem 3. tekil şahıs zamiri olarak kullanılan "ol" zamirinin ilk kullanımı Göktürk yazıtlarında tespit edilmiştir. Eski Anadolu Türkçesinin son dönemlerinde "o" biçimine dönüştüğü iddia edilse de (Küçük, 2014:8) Eski Uygur Türkçesinde hem "ol" hem "o" şekli ile kullanıldığı tespit edilmiştir (Caferoğlu, 2015:138). Göktürkçede ol (Tekin, 2003:119), Eski Uygur Türkçesinde ol, o (Caferoğlu, 2015:138), Karahanlı Türkçesinde ol (Hacieminoğlu, 2013:37), Eski Anadolu Türkçesinde ol, o (Öztürk, 2017:83), Harezm Türkçesinde ol (Ata, 2002:67), Kıpçak Türkçesinde ol, o (Toparl1, Vural, Karaatlı, 2014:203-204), Çağatay Türkçesinde ol (Eckmann, 1988:272).

Türkiye Türkçesi yazı dilinde "o" şekline dönüşen "ol" zamiri, Risale-i Elfaz-1 Küfür'de "ol" şeklinde kullanılmıştır: ol 10a/8 (RK)

șagalt- "İyileştirmek" anlamına gelen bu fiil, Eski Uygur Türkçesi döneminden beri kullanılan sag "săg, sağlam" (Caferoğlu, 2015:193) kelimesinden türemiştir. Eski Anadolu Türkçesinde șag̉alt- (Özkan, 2014:427), Harezm Türkçesinde "düzeltmek" anlamıyla; saġalt- (Yüce, 1993:171), Kıpçak Türkçesinde "iyileşmek" anlamıyla; șaġal- (Toparlı, Vural, Karaatlı, 2014:222).

$\mathrm{Bu}$ fiil Türkçe Sözlük'te yer almasına rağmen, Türkiye Türkçesi yazı dilinde kullanılmamaktadır. $\mathrm{Bu}$ fiil Risale-i Elfaz-1 Küfür'de bir yerde geçmiştir; șagaltdı 27a/4 (RK)

țamu: "Cehennem" anlamına gelen bu kelime, Eski Uygur Türkçesi döneminden itibaren görülür. Eski Uygur Türkçesinde tamu (Caferoğlu, 2015:223), Karahanlı Türkçesinde tamu (Atalay, 1985:234), Eski Anadolu Türkçesinde țamu (Gaddar, 2012:573), Harezm Türkçesinde țamug (Ata, 2014:402), Kıpçak Türkçesinde tamu, tamuk, tamug tamuh, tamuv (Toparlı, Vural, Karaatl1, 2014:260-261), Çağatay Türkçesinde tamug், tamuḳ (Güzeldir, 2002:225).

Türkiye Türkçesi yazı dilinde kullanımdan düşmüş olan bu kelime Risale-i Elfaz-1 Küfür'de bir yerde geçer; țamuda 39b/1 (RK)

türküce: "Türkçe" anlamına gelen bu kelime, mevcut şekliyle tarihî Türk lehçelerinde tespit edilememiştir. Eski Uygur Türkçesinde türkçä (Caferoğlu, 2015:259), Karahanlı Türkçesinde türkī, türkçe (Üşenmez, 2006:472), Eski Anadolu Türkçesinde türkçe, türkī, türkice (Gaddar, 2012:590), Harezm Türkçesinde Türkçe 
(Yüce, 1993:192), Kıpçak Türkçesinde türkī, türkişe (Toparlı, Vural, Karaatl, 2014:287), Çağatay Türkçesinde türkì (Berbercan, 2011:555).

Türkiye Türkçesinde yazı dilinde "Türkçe" şeklinde kullanılan bu kelime Risale-i Elfaz-1 Küfür'de kullanıldığı şekliyle başka bir yerde tespit edilememiştir; türküce 1b/7 (RK)

yu- Eski Uygur Türkçesinden itibaren kullanılan bu fiil "yıkamak" anlamına gelir. Eski Uygur Türkçesinde yu- (Caferoğlu, 2015:305), Karahanlı Türkçesinde yu(Üşenmez, 2006:481), Eski Anadolu Türkçesinde yu- (Özkan, 2014:585), Harezm Türkçesinde yu- (Sağol, 1993:1042), Kıpçak Türkçesinde yu- (Toparlı, Vural, Karaatl1, 2014:328), Çağatay Türkçesinde (Berbercan, 2011:583).

Türkiye Türkçesi yazı dilinde kullanımdan düşen yu- fiili, Risale-i Elfaz-1 Küfür'de bir yerde geçer; yuyup 4b/13 (RK)

\section{Sonuç}

Türk dili, tarih boyunca geniş bir coğrafyaya yayılmış, yayıldı̆̆ coğrafyada gelişmiş̧ ve bu geliş̧melere bağlı olarak bir takım değişimlere maruz kalmıştır. Bir dildeki değişimleri görmenin temel şartı, o dilin arkaik unsurlarını tespit etmektir. Bir dilin arkaik unsurları, o dili konuşan toplumun duyuş-düşünüş şeklini göstermenin yanı sıra, sahip oldukları kültürel zenginlikleri de gözler önüne serer. Yapılan bu çalışmada Risale-i Elfaz-1 Küfür'deki arkaik unsurlar incelenmiş, bu inceleme neticesinde şu sonuca ulaşılmıştır; Risale-i Elfaz-1 Küfür'de 6's1 ek, 15'i kelime olmak üzere toplam 21 tane arkaik unsur tespit edilmiştir. Tespit edilen bu arkaik unsurlardan pek çoğunun kullanımı Eski Uygur Türkçesinden itibaren görülmektedir. Yine bazı arkaik unsurların kullanımı, Türkçenin ilk yazılı belgelerine kadar götürülebilirken, bazılarının kullanımı daha geç dönemlerde görülmektedir. Örneğin, söz konusu eserde geçen -gIl emir ekini Göktürk Yazıtları'nda da görmek mümkünken, -IcAk zarf fiil ekinin kullanımı Eski Anadolu Türkçesinden itibaren görülmektedir. Ayrıca, tespit edilen arkaik unsurların tarihî Türk lehçelerinin tamamında veya bir kısmında görülmesi, Türk dilin sürekliliğini göstermesi bakımından da oldukça önemlidir.

\section{Kisaltmalar}

RK: Risale-i Elfaz-1 Küfür.

\section{Kaynakça}

ALAN, İ. (2018). Risale-i Elfaz-ı Küfür (İnceleme-Metin-Sözlük). Yayımlanmamış Yüksek Lisans Tezi, Elazığ: Fırat Üniversitesi Sosyal Bilimler Enstitüsü

ARAT, R. A. (2006). Atabetü'l-Hakayık, Ankara: TDK Yay. İstanbul: 36.

ATA, A. (2002). Harezm-Altınordu Türkçesi, Türk Dilleri Araştırmaları Dizisi, ATA, A. (2014). Nehcü'l-Feradis, Dizin-Sözlük. Ankara: TDK Yay.

ATALAY, B. (1985). Divanü Lügat-it-Türk Tercümesi I. Ankara: TDK Yay.

BERBERCAN, M. T. (2011). Çağatayca Gülistan Tercümesi (Gramer-Metin-Dizin). Yayımlanmamış Doktora Tezi, İstanbul: İstanbul Üniversitesi Sosyal Bilimler Enstitüsü.

BURAN, A.; ALKAYA, E. (2015). Çağdaş Türk Lehçeleri. Ankara: Akçağ Yay. 
Büyük Türkçe Sözlük http://sozluk.gov.tr/ (erişim tarihi: 06.08.2019). Anı Yay.

DEMIRCİ, K. (2015). Türkoloji İçin Dilbilim-Konular Kavramlar Teoriler. Ankara:

GADDAR, Z. (2012). Süheyl ü Nevbahār'ın Dilbilgisel Özellikleri ve Dizini. Yayımlanmamış Doktora Tezi, Denizli: Pamukkale Üniversitesi Sosyal Bilimler Enstitüsü.

GÜZELDİR, M. (2002). Abuşka Lüğatı (Giriş-Metin-İndeks). Yayımlanmamış Doktora Tezi, Erzurum: Atatürk Üniversitesi Sosyal Bilimler Enstitüsü.

HACIEMINOĞLU, E. (2013). Karahanlı Türkçesi Grameri. Ankara: TDK Yay.

ECKMANN, J. (1988). Çağatayca El Kitabı (Günay Karaağaç, Haz.). İstanbul: Edebiyat Fakültesi Basım Evi.

ECKMANN, J. (2014). Harezm, Kıpçak ve Çağatay Türkçesi Üzerine Araştırmalar. Ankara: (Osman Fikri Sertkaya, Haz.), TDK Yay.

KAYA, F. (2016). Kanunnâme-i Âl-i Osman'da Geçen Arkaik (Eskicil) Kelimeler Üzerine Bir İnceleme. Tarih Okulu Dergisi (TOD), Y11 9, Sayı XXV, s. 155-176.

KORKMAZ, Z. (2013). Türkiye Türkçesinin Temeli Oğuz Türkçesinin Gelişimi. Ankara: TDK Yay.

KORKMAZ, Z. (2003). Gramer Terimleri Sözlügü. Ankara: TDK Yay.

KÜÇÜK, S. (2014). Şeyyad Hamza'nın Yusuf u Züleyha'sındaki Arkaik Unsurlar. Atatürk Üniversitesi, Türkiyat Araştırmaları Enstitüsü Dergisi (TAED), Say1 50, s.1-25.

ÖZKAN, E. (2014). Dede Korkut Kitabı'nın Vatikan Nüshasının Tarihî ve Etimolojik Sözlüğü. Yayımlanmamış Yüksek Lisans Tezi, Sakarya: Sakarya Üniversitesi, Sosyal Bilimler Enstitüsü.

ÖZTÜRK, E. (2017). Eski Anadolu Türkçesi El Kitabı. Ankara: TDK Yay.

SAĞOL, G. (1993). Harezm Türkçesi Satırarası Kuran Tercümesi (Giriş-Metin-Sözlük). Yayımlanmamış Doktora Tezi, İstanbul: Marmara Üniversitesi Türkiyat Araştırmaları Enstitüsü.

SALAN, E. (2012). Eski Anadolu Türkçesinde dUK ve UK Eklerinin İşlevsel Denkliği. International Periodical For The Languages, Literature and History of Turkish or Turkic 7/4, Ankara, s. 2697-2708.

TEKINN, T. (2003). Orhon Türkçesi Grameri. (Mehmet Ölmez, Yay.) Türk Dilleri Araştırmaları Dizisi: 9, İstanbul. Yay.

TOPARLI, R., Vural, V., Karaatlı, R. (2014). Kıpçak Türkçesi Sözlü̆̆̈̈. Ankara: TDK

YÜCE, N. (1993). Mukaddimetü'l-Edeb. Ankara: TDK Yay.

ÜŞENMEZ, E. (2006). Karahanlı Türkçesi Sözlügü. Yayımlanmamış Yüksek Lisans Tezi, Kütahya: Dumlupınar Üniversitesi Sosyal Bilimler Enstitüsü. 